\title{
Burden of eclampsia: a persisting problem in the developing countries
}

\author{
Kavita Babbar1*, Meena Armo1, Madhumita Murthy ${ }^{2}$
}

\author{
${ }^{1}$ Department of Obstetrics \& Gynecology, ${ }^{2}$ Department of Anaesthesia, Chhattisgarh Institute of Medical Sciences \\ (CIMS), Bilaspur, Chhattisgarh-495001, India
}

Received: 13 May 2015

Accepted: 06 June 2015

\author{
*Correspondence: \\ Dr. Kavita Babbar, \\ E-mail: drsonal.babbar@gmail.com
}

Copyright: (c) the author(s), publisher and licensee Medip Academy. This is an open-access article distributed under the terms of the Creative Commons Attribution Non-Commercial License, which permits unrestricted non-commercial use, distribution, and reproduction in any medium, provided the original work is properly cited.

\begin{abstract}
Background: Hypertensive disorders of pregnancy constitute one of the major threats to maternal health. Eclampsia is still a leading cause of maternal morbidity and mortality in developing countries. This study was carried out to determine the incidence of eclampsia, demographic profile of patients, obstetric outcome, fetal outcome, maternal morbidity and mortality.

Methods: A 5 year retrospective observational study included 521 patients who presented in emergency with eclampsia and admitted between April 2010 and March 2015, in the department of Obstetrics and gynecology, government medical college (Chhattisgarh institute of medical sciences) and tertiary care hospital Bilaspur, Chhattisgarh.

Results: Based on 14,876 pregnancies in the 5 year period in our referral hospital, we estimated an incidence of $3.5 \% .70 .8 \%$ were primigravida and $86.4 \%$ of patients had no regular antenatal care. Majority of the cases $(82.1 \%)$ presented as antepartum/intrapartum eclampsia in the age group 20-24 years (65.4\%). The patients usually presented at term $(62.4 \%)$ with $69.7 \%$ having vaginal delivery as compared to $30.3 \%$ undergoing LSCS. The fetal outcome showed $56.2 \%$ live-births, $25.5 \%$ had early neonatal death and $13.3 \%$ still-born. The complications most commonly observed were puerperal sepsis ( $11 \%$ ),oliguria( $8.1 \%)$, pulmonary edema(5.9\%) and maternal mortality as $8.4 \%$.

Conclusions: Most of the life-threatening eclampsia cases can be prevented by simple awareness and motivation towards antenatal care. In Chhattisgarh state where majority of rural population are tribal, illiterate, living in difficult to reach areas, delay in referral, due to unavailability of clinicians or medical officers in peripheral areas for antenatal examination. The best way to reduce the burden is by creating an awareness, proper antenatal care, timely referral and thus prevent the occurrence of eclampsia.
\end{abstract}

Keywords: Eclampsia, Burden, Maternal morbidity

\section{INTRODUCTION}

Varadaeus coined the term 'eclampsia' derived from the Greek word which means "like a flash of lightening". Eclampsia is defined as the occurrence of convulsion /coma not caused by any coincidental neurological disease such as epilepsy in a woman whose condition meets the criteria for pre-eclampsia. ${ }^{1}$

Hypertensive disorders complicate $7 \%-9 \%$ of all pregnancies. Hypertensive disorder is the leading cause of maternal mortality in India, accounting for more than
$8 \%$ of maternal deaths. The identification and effective management of this entity play a significant role in both maternal and fetal outcome. It has been estimated that infants born to women with pre-existing or gestational hypertension have a $16 \%$ risk of perinatal death or serious morbidity and with $36 \%$ of them needing "highlevel" neonatal care. ${ }^{2}$

The pathophysiology is still poorly understood and it is difficult to determine risk factors including the primiparity is surely one to consider. ${ }^{3}$ Eclampsia can manifest itself in unusual and unpredictable in well- 
monitored patients without risk factors. The diagnosis must be made quickly for taking urgent and appropriate obstetric management. ${ }^{3}$

The primary objective of the present study was to determine the incidence along with maternal and fetal outcome of eclampsia at a tertiary care referral hospital and thus quantifying the magnanimity with clinical relevant pointers which can help in improving the health care delivery. This study highlights the need to strengthen the quality of health care in hypertensive disorders of pregnancy in context to the Indian health care setting especially in rural areas like our state.

\section{METHODS}

A 5 year retrospective observational study included 521 patients presenting as eclampsia who were admitted between April 2010 and March 2015 as an emergency, in the department of obstetrics and gynecology of Chhattisgarh institute of medical sciences a government medical college and $2^{\text {nd }}$ biggest tertiary care hospital. Each case was thoroughly evaluated on the basis of age, residence, education, socio-economic status, previous antenatal care, gestational age at the time of presentation, parity. After a thorough examination and appropriate investigation, the appropriate conservative/ medical or surgical management was done and the details of the outcome including maternal morbidity, mortality, fetal outcome were recorded and discussed. Qualitative data were presented as frequencies and percentages.

\section{RESULTS}

The present study was conducted in the department of obstetrics and gynecology, a government medical college (Chhattisgarh institute of medical sciences) and tertiary care hospital, Bilaspur, Chhattisgarh, from April 2010 to March 2015. Out of 14,876 cases of institutional deliveries observed over a period of 5 years, 521 (3.5\%) women had presented as eclampsia in the emergency to our institute and later investigated and managed in the hospital.

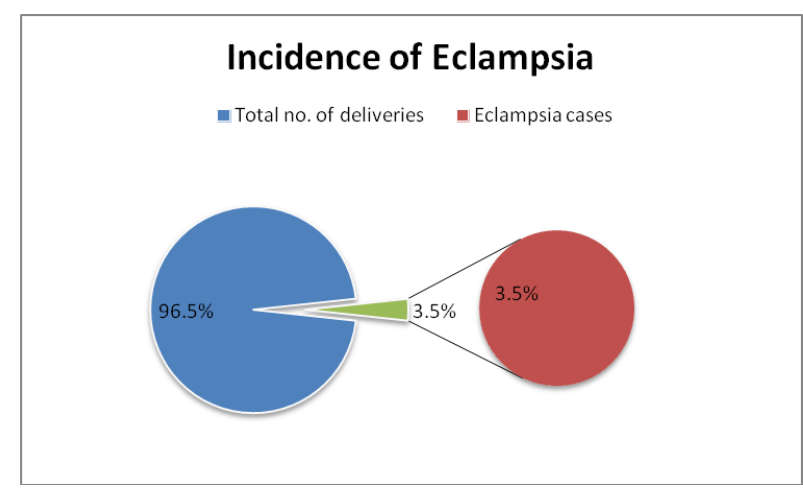

Figure 1: Incidence of eclampsia.

The incidence of eclampsia was found as 3.5\% (Figure 1). The most common age at presentation was 20-25 years 341 (65.4\%)in our study. Majority of patients were uneducated $443(85.1 \%)$, belonged to rural area 464 $(89.1 \%)$ and from low socioeconomic background 368 (70.6\%). (Table 1)

Table 1: Demographic details $\mathbf{N = 5 2 1}$.

\begin{tabular}{|lll|}
\hline \multicolumn{2}{|l|}{ Frequency } & Percentage \\
\hline Age in years & & \\
\hline $15-19$ & 53 & 10.2 \\
\hline $20-24$ & 341 & 65.4 \\
\hline $25-29$ & 89 & 17.2 \\
\hline $30-34$ & 28 & 5.3 \\
\hline$>35$ & 10 & 1.9 \\
\hline Educational status & & \\
\hline Educated & 78 & 14.9 \\
\hline Uneducated & 443 & 85.1 \\
\hline Residence & & \\
\hline Urban & 57 & 10.9 \\
\hline Rural & 464 & 89.1 \\
\hline $\begin{array}{l}\text { Socio-economic } \\
\text { status }\end{array}$ & \\
\hline Low & 368 & 70.6 \\
\hline Lower- middle & 106 & 20.4 \\
\hline Middle & 47 & 9 \\
\hline
\end{tabular}

In our study, majority $369(70.8 \%)$ were nulliparous, $152(29.2 \%)$ women were multiparous. The gestational age at presentation observed most commonly was $>37$ weeks in $325(62.4 \%)$ patients and $450(86.4 \%)$ did not receive any antenatal care whereas only $71(13.6 \%)$ had antenatal care. (Table 2)

Table 2: Parity, gestational age, previous antenatal care $(\mathrm{N}=\mathbf{5 2 1})$.

\begin{tabular}{|lll|}
\hline \multicolumn{2}{|l}{ Prequency } & Percentage \\
\hline Nurity & & \\
\hline Multiparous & 369 & 70.8 \\
\hline $\begin{array}{l}\text { Gestational age } \\
\text { (wks) }\end{array}$ & 152 & 29.2 \\
\hline $20-25$ & 19 & 3.7 \\
\hline $26-31$ & 79 & 15.2 \\
\hline $32-37$ & 98 & 18.7 \\
\hline$>37$ & 325 & 62.4 \\
\hline $\begin{array}{l}\text { Previous } \\
\text { antenatal care }\end{array}$ & & \\
\hline Booked & 71 & 13.6 \\
\hline $\begin{array}{l}\text { Unbooked/ } \\
\text { Irregular ANC }\end{array}$ & 450 & 86.4 \\
\hline
\end{tabular}

Majority 428(82.1\%) presented as antepartum/ intrapartum eclampsia and $93(17.9 \%)$ as postpartum eclampsia (Figure 2)

The most commonly observed mode of delivery was normal $(69.7 \%)$, and $30.3 \%$ had caesarean section (Figure 3). 


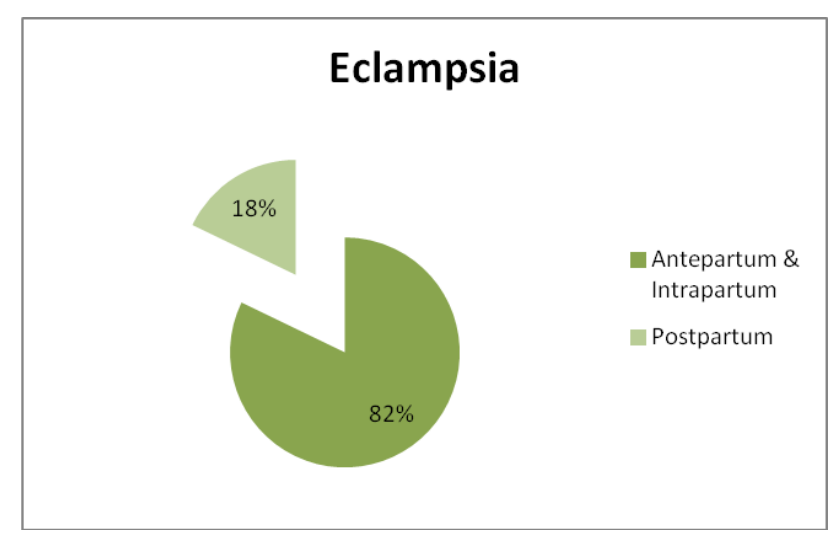

Figure 2: Type of presentation.

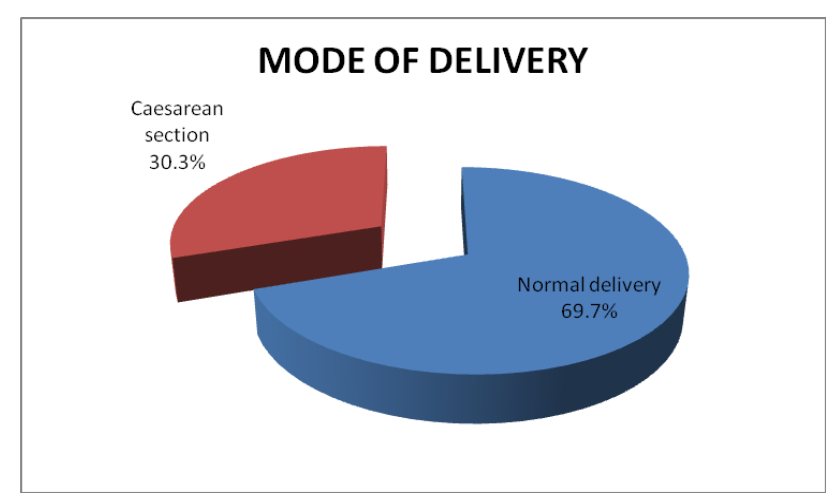

Figure 3: Mode of delivery.

The fetal outcome was live-births in 372(72.5\%), still born in $96(18.7 \%)$ and early neonatal death in $45(8.8 \%)$ patients whereas 8 patients died undelivered only. (Table 3 )

Table 3: Fetal outcome.

\begin{tabular}{|ll|l|}
\hline & Frequency & Percentage \\
\hline Live-born & 372 & 72.5 \\
\hline Still born & 96 & 18.7 \\
\hline Neonatal death & 45 & 8.8 \\
\hline
\end{tabular}

Overall major complications observed was puerperal sepsis (11\%), oliguria (8\%), pulmonary edema (6\%), HELLP $(4.8 \%)$, postpartum haemorrhage $(3.6 \%)$, postpartum psychosis $(1.3 \%)$ and CVA $(1.1 \%)$. (Table 4). The maternal mortality rate due to eclampsia was $44(8.4 \%)$.

Table 4: Major Complications* and mortality ( $\mathbf{N}=521)$.

\begin{tabular}{|lllll|}
\hline $\begin{array}{l}\text { Complication } \\
\text { Puerperal } \\
\text { sepsis }\end{array}$ & 58 & 11.1 & 13 & 2.5 \\
\hline Oliguria & 42 & 8.1 & 6 & 1.1 \\
\hline $\begin{array}{l}\text { Pulmonary } \\
\text { edema }\end{array}$ & 31 & 5.9 & 8 & 1.5 \\
\hline HELLP & 25 & 4.8 & 12 & 2.3 \\
\hline PPH & 19 & 3.6 & 2 & 0.3 \\
\hline $\begin{array}{l}\text { Post-partum } \\
\text { psychosis }\end{array}$ & 7 & 1.3 & 2 & 0.3 \\
\hline CVA & 6 & 1.1 & 1 & 0.2 \\
\hline
\end{tabular}

\section{DISCUSSION}

Hypertensive disorders of pregnancy constitute a perplexing and clinically challenging group of pregnancy complications that are responsible for a substantial burden of illness in developed as well as underdeveloped countries of the world. They are still a leading cause of maternal and perinatal mortality worldwide.

During the past 50 years, there has been a significant reduction in the rates of eclampsia, maternal mortality, and maternal morbidity in the developed countries. In contrast, the rates of eclampsia, maternal complications, and maternal mortality remain high in the developing countries. $^{4}$

Incidence of hypertensive disorders in India is found to be $10.08 \%$ as observed through the data collected by the National Eclampsia Registry (NER) (11,266 out of $1,11,725$ deliveries) over the past 3 years $2.3 \%$ presenting with eclampsia. ${ }^{5}$

The higher incidence (3.5\%) in our set-up is due to lower compliance with antenatal clinic attendances and very few having access to specialist care. A survey of recentlydelivering mothers recorded a history of eclampsia in $3.2 \%$ pregnancies/ deliveries by Chaturvedi etal. ${ }^{6}$

In Chhattisgarh, of 25.5 milion population $78 \%$ live in rural areas, $37 \%$ account for tribal population. As per APIP 2012-2013 Chhattisgarh, there are 27 districts, 146 blocks, and 20,308 villages. More than half of these districts have been classified as remote, tribal, and extremist affected areas. ${ }^{6}$ As in our study which also revealed $89.1 \%$ from rural areas, $85.1 \%$ uneducated and $70.6 \%$ from low socioeconomic status who have lack of resources, lack of access and awareness to medical care. ${ }^{7}$

In our study $75.6 \%$ were $<25$ years and nulliparous (70\%), the same was reported by Rasaly et al. \& Warden et al. in $2002 .^{8,9}$

In a study eclampsia was common in young pregnant woman between $19-24$ years $(83 \%)$ by Chaturvedi et al. ${ }^{6}$ Eclampsia was a disease of primigravida majority of women $67 \%$ in our study were primigravida which is comparable to study by Sheraz's et al. 69.1\%, Datta MR et al $66 \%$ and Shaheen et al. $69 \% .^{10-12}$

Most studies found that eclampsia occurred in the extremes of ages.

Most commonly the presentation was at term (62.4\%) gestation in our study similar to study by Choudhary etal who revealed eclampsia was commonest at term pregnancy $(72.34 \%)$ in their study. ${ }^{13}$

The study demonstrated by the finding that $86.4 \%$ of the patients in this study were unbooked for antenatal care similar to $88.9 \%$ in study by Tuffnell etal who suggested 
that adequate antenatal care facilitates early identification of risk factors and appropriate intervention to prevent progression to eclampsia. ${ }^{14}$

Antenatal care has been identified as the single intervention which could influence the maternal mortality of our country. Many women still seem to be unreached with this basic pregnancy evaluation. ${ }^{5}$

The FOGSI-ICOG NER has brought forth some revealing trends by national sample surveys number of cases of eclampsia is more than cases of imminent eclampsia which points to the lost opportunities of prevention. ${ }^{5}$

In our study $82 \%$ had antepartum/intrapartum eclampsia. Joshi etal also showed $89.7 \%$ of the women had ante partum and intrapartum eclampsia. As the precise diagnosis of the onset of labour was not easily ascertainable and as eclampsia per se increases the uterine contractility and leads to premature labour, a discrete overlap between the ante partum and the intrapartum cases may exist. Postpartum eclampsia accounted for $10.3 \%$ of the cases. ${ }^{15}$

Antenatal eclampsia (76.78\%); post-partum convulsions $(13.72 \%)$ are also significant. ${ }^{5}$

428 cases $(82.1 \%)$ of eclampsia was ante-partum/ intrapartum and 93 cases $(17.9 \%)$ were postpartum. This was similar to what was reported what was reported by Douglas \& Redman. ${ }^{16}$ Lower post partum eclampsia was reported earlier $10.6 \%$ by El Nafaty. ${ }^{17}$

The mode of delivery in our patients was by vaginal route in $69.7 \%$ similar to study by that demonstrated vaginal delivery was the most common mode of delivery followed by caesarean section. $63 \%$ had vaginal delivery followed by $27 \%$ by LSCS. ${ }^{18}$

In our study perinatal mortality was $27.5 \%$ comparable to $300 / 1000$ of perinatal death in another study and by Yaliwal et al of 350/1000. ${ }^{18,19}$

Late arrival of patients after onset of fits results in severe intrauterine hypoxia and intrauterine death. Eclampsia occurring preterm necessitates preterm delivery. Available neonatal care facilities also determines the perinatal outcome.

The most common complications observed were puerperal sepsis $(11 \%)$, oliguria $(8 \%)$, pulmonary edema (6\%), HELLP (4.8\%) similar to most common complication in other study revealed was post partumpyrexia. $12 \% .^{18}$

In eclampsia the major maternal complications included abruptio placentae (10\%), HELLP (hemolysis, elevated liver enzymes, and low platelet count) syndrome (11\%), disseminated intravascular coagulopathy $(6 \%)$, pulmonary edema $(5 \%)$ and acute renal failure $(4 \%) .{ }^{20}$
Despite all measures taken to rectify the complications, 44 patients could not survive giving a mortality rate of $8.4 \%$. Maternal mortality of $8.4 \%$ in present study is comparable to that of Somegowda $(5.4 \%)$ and less as reported by Nobis $\mathrm{PN}(11.54 \%) .^{21,22}$

Our state being one of the nine low performing states which together account for about half of India's population and $12 \%$ of global maternal deaths $(62 \%$ of India's total maternal deaths and $70 \%$ of her infant deaths) (Registrar General and Census Commissioner, $2011 b) .^{23}$

The case fatality rate (number of deaths/number of cases) of eclampsia ranges from $0-1.8 \%$ in high-income countries up to $17.7 \%$ in India, emphasizing a huge gap in the quality of maternal health care according to social and economic pattern. ${ }^{24}$

\section{CONCLUSION}

Eclampsia is a dreadful complication of pregnancy occupying the centre stage of obstetric attention. Eclampsia is difficult to predict and treat likely because of our lack of understanding of its underlying cause but appropriate and timely standard preventive therapy can avert eclampsia in virtually all patients with gestational hypertension.

As majority of the pregnant women presenting to our health facility are illiterate with only rudimentary medical knowledge of their own pregnancies. Most of the maternal deaths and complications are due to lack of prenatal care, lack of access to hospital care, lack of resources, inappropriate diagnosis and management.

Antenatal care has been identified as the single intervention which could influence the maternal mortality of our country. The need of the hour is to train medical officers, birth attendants, and paramedical personnel in remote interiors to create awareness, provide antenatal care and handle obstetric emergencies.

The treatment of this disease calls for the need to focus especially in the resource challenged settings, reject their adversities to help manage this deadly disease more efficiently.

Improved screening, preventive and treatment strategies may not only optimize management of hypertensive pregnancy disorders but also have long term impact on women's cardiovascular events and outcomes years after the affected pregnancies.

\section{ACKNOWLEDGEMENTS}

We sincerely thank Lt. Col. (Prof.) Dr S. K. Mohanty, Dean and Prof. Dr R. Murthy, Medical superintendent CIMS, for granting permission. We also thank all interns for collecting the records. 
Funding: No funding sources

Conflict of interest: None declared

Ethical approval: The study was approved by the Institutional Ethics Committee

\section{REFERENCES}

1. Mordechai Hallak: Hypertension in pregnancy. High risk pregnancy: management option, Second edition (1999) W.B. Saunders; 639-663.

2. Magee LA, von Dadelszen P, Chan S, Gafni A, Gruslin A, Helewa M, et al. CHIPS Pilot Trial Collaborative Group. The control of hypertension in pregnancy study pilot trial. Br J Obstet Gynaecol. 2007;114:e13-20.

3. Ducarme G, Herrnberger S. Eclampsia: retrospective study of 16 cases. Obs and gynecology Fertility. 2009;37(1):11-17.

4. Ghulmiyyah L, Sibai B. Maternal Mortality From Preeclampsia/Eclampsia Seminars in Perinatology. 2012;36(1):56-9.

5. Gupte S, Waugh G. Preeclampsia-Eclampsia. Journal of Obstetrics and Gynaecology of India. 2014;64(1):4-13.

6. Chaturvedi S, Randive B, Mistry N. Availability of treatment for eclampsia in public health institutions in Maharashtra. India. J Health Popul Nutr. 2013;31(1):86-95.

7. Annual Health Survey 2011-2012 fact: Chhattisgarh office of the Registrar General and Census Commission. Vital statistics division, New Delhi, India.

8. Rasaly S, Carson-Dewitt. Pre-eclampsia \& eclampsia. Gale Encyclopedia of Medicine. 23-40.

9. Warden M, Euerle B. Pre eclampsia (Toxaemia of pregnancy) emergency Medicine 2003. Updated on April 52002.

10. Sheraz S, Boota M. Shahzad S. Eclampsia. Prof Med J. 2006.13(1):27-31.

11. Datta MR, Pant L, Kabiraj M, Basu SB. Magnesium sulfate in eclampsia: A safe, efficient and costeffective approach. J Obst Gynecol India. 2002;52(3):65-8.

12. Shaheen B. Hassan L, Obaid M. Eclampsia, a major cause of maternal and perinatal mortality: A prospective analysis at a tertiary care hospital of Peshawar. J Pak Med Assoc. 2003;53:346.

13. Choudhary P. Eclampsia: A hospital based retrospective study. Kathmandu University Medical Journal. 2003;1(4):237-41.
14. Tuffnell DJ, Jankowisz D, Lindow SW. Outcomes of severe pre-eclampsia/eclampsia in Yorkshire 1999/2003. BJOG: An International Journal of Obstetrics \& Gynaecology. 2005;112(7):875-80.

15. Joshi Suyajna D, Veerendrakumar CM. 'Single Dose MgSo4 Regimen' for Eclampsia - A Safe Motherhood Initiative. J Clin Diagn Res. 2013;7(5):868-72.

16. Douglas KA, Redman CW. Eclampsia in the United Kingdom. BMJ. 1994;309:1395.

17. El Nafaty AU, Melah GS, Massa AA, Audu BM, Nelda M. The analysis of eclamptic Morbidity and Mortality in the Specialist Hospital Gombe, Nigeria. J Obstet gynaecol. 2004;24(2):142-7.

18. Pradeep MR, Lalitha S. Retrospective Study of Eclampsia in a Teaching Hospital. International Journal of Recent Trends in Science and Technology. 2013;8(3):171-3.

19. Yaliwal RG, Jaju PB, Vanishree M. Eclampsia and Perinatal Outcome A Retrospective Study in a Teaching Hospital Journal of Clinical and Diagnostic Research. 2011;5(5):1056-9.

20. Mattar F, Sibai BM. Eclampsia. VIII. Risk factors for maternal morbidity. Am J Obstet Gynecol. 2000;182:307-12.

21. Gaddi SS, Somegowda. Maternal and perinatal outcome in eclampsia in a district hospital. J Obst Gyn Ind. 2007:57(4):324-26.

22. Nobis PN. Maternal outcome in eclampsia. Obstet. Gynecol Asia. 2002;6(1):25-8.

23. Registrar General and Census Commissioner, 2011b. Presentation on Annual Health Survey Fact Sheet Key Findings, Annual Health Survey 2010e11, Ministry of Home Affairs. Government of India, New Delhi.

24. Ronsmans C, Campbell O. Quantifying the fall in mortality associated with interventions related to hypertensive diseases of pregnancy. BMC Public Health. (2011),11(3).

Cite this article as: Babbar K, Armo M, Murthy M. Burden of Eclampsia: a persisting problem in the developing countries. Int J Reprod Contracept Obstet Gynecol 2015;4:1029-33. 